\title{
The dopamine hypothesis of drug addiction and its potential therapeutic value
}

\author{
Marco Diana* \\ 'G. Minardi' Cognitive Neuroscience Laboratory, Department of Drug Sciences, University of Sassari, Sassari, Italy
}

\section{Edited by:}

Lorenzo Leggio, Brown University, USA

\section{Reviewed by:}

Diana Martinez, Columbia University, USA

Frederic Woodward Hopf, University of California at San Francisco, USA

*Correspondence:

Marco Diana, 'G. Minardi' Cognitive Neuroscience Laboratory,

Department of Drug Sciences, University of Sassari, Via Muroni

n. 23, Sassari, Italy.

e-mail:dsfdiana@uniss.it
Dopamine (DA) transmission is deeply affected by drugs of abuse, and alterations in DA function are involved in the various phases of drug addiction and potentially exploitable therapeutically. In particular, basic studies have documented a reduction in the electrophysiological activity of DA neurons in alcohol, opiate, cannabinoid, and other drug-dependent rats. Further, DA release in the Nucleus accumbens (Nacc) is decreased in virtually all drug-dependent rodents. In parallel, these studies are supported by increments in intracranial self stimulation (ICSS) thresholds during withdrawal from alcohol, nicotine, opiates, and other drugs of abuse, thereby suggesting a hypofunction of the neural substrate of ICSS. Accordingly, morphological evaluations fed into realistic computational analysis of the medium spiny neuron of the Nacc, post-synaptic counterpart of DA terminals, show profound changes in structure and function of the entire mesolimbic system. In line with these findings, human imaging studies have shown a reduction of dopamine receptors accompanied by a lesser release of endogenous DA in the ventral striatum of cocaine, heroin, and alcohol-dependent subjects, thereby offering visual proof of the "dopamine-impoverished" addicted human brain. The lasting reduction in physiological activity of the DA system leads to the idea that an increment in its activity, to restore pre-drug levels, may yield significant clinical improvements (reduction of craving, relapse, and drug-seeking/taking). In theory, it may be achieved pharmacologically and/or with novel interventions such as transcranial magnetic stimulation (TMS). Its anatomo-physiological rationale as a possible therapeutic aid in alcoholics and other addicts will be described and proposed as a theoretical framework to be subjected to experimental testing in human addicts.

Keywords: addiction, dopamine, rTMS, dopamine agents, VTA, prefrontal cortex
Drug addiction is a brain disease that produces profound modifications in human behavior (Hyman, 2007; Koob and Volkow, 2010), with important negative consequences at various levels, including personal health, employment, family interactions, and society in general (Chandler et al., 2009). Therapeutic possibilities for this devastating illness are, with some rare exceptions, limited to pharmacologic treatments that are largely unsatisfactory (Koob et al., 2009; Leggio et al., 2010; Swift, 2010). From here the necessity to develop new therapeutic hypothesis/interventions independent from those commonly employed.

Transcranial magnetic stimulation (TMS), through generation of an electromagnetic field capable of crossing painlessly through the skull and influencing the underlying brain matter, appears to be a promising candidate for treating addictive behaviors (Barr et al., 2008; Feil and Zangen, 2010) and other brain diseases (Kobayashi and Pascual-Leone, 2003). In brief, this relatively new method allows modulation of discrete brain areas of the awake and conscious subject under study. The pulsatile electromagnetic field generated around the coil crosses the skull and is capable of directly exciting/inhibiting neurons in the underlying cortices (Padberg and George, 2009). Commonly employed as a research tool, TMS is recently affirming its role as a potential therapeutic means approved by the Food and Drug Administration for brain pathologies such as drug-resistant major depression, bipolar syndrome, and negative symptoms of schizophrenia. In the drug addiction field, the therapeutic potential of TMS has been tested in nicotine-dependent subjects (Lang et al., 2008; Amiaz et al., 2009), cocaine addicts (Boutros et al., 2001, 2005; Sundaresan et al., 2007; Politi et al., 2008), and alcoholics (Conte et al., 2008; Mishra et al., 2010). Although the results are certainly encouraging, the disparity of clinical outcomes evaluated in different studies and diversity of pattern/site/methodology of stimulation precludes direct comparisons and hampers firm conclusions. However, in those studies in which craving was measured (Politi et al., 2008; Amiaz et al., 2009; Mishra et al., 2010) significant reductions have been found, thus encouraging further experimental scrutiny. At present, we are evaluating anti-craving and alcohol-intake efficacy of TMS in alcoholics (Addolorato et al., in preparation), short and long-term cocaine intake in treatment-seeking cocaine addicts (Pedetti et al., in preparation), and money/cocaine choice in a lab study of cocaine addicts nonseeking treatment (Martinez et al., in preparation). Nevertheless, the brain site(s) to be stimulated/inhibited and the stimulation parameters (i.e., frequency of stimulation, number of session etc.,) are matters of intense debate and an appropriate rationale is needed. 


\section{DOPAMINE AS A POSSIBLE THERAPEUTIC TARGET}

The role of central DA systems in the acute effects of drugs of abuse was recognized long ago (Wise, 1980, 1987; Di Chiara and Imperato, 1988). Even before (Ahlenius et al., 1973), attempts were made to prevent human alcohol-induced euphoria through administration of the DA synthesis inhibitor alpha methyl-para-tyrosine. Although theoretically ineccepibile, this approach (reduction of drug-induced DA increments to prevent abuse) is unlikely to have a practical validity as any compound with DA antagonistic (i.e., neuroleptics) properties is known to be aversive in humans. On the other hand, widely documented experimental evidence suggests that the mesolimbic dopamine system is "hypofunctional" in the addicted brain (Melis et al., 2005). In brief, the hypothesis contends that decreased DA function in addicted subjects results in a decreased interest to non-drug-related stimuli and increased sensitivity to the drug of choice (Melis et al., 2005), leading to propose that restoring DA function might be therapeutically advantageous.

Alcohol-dependent (in the present context the term "dependent," when referred to a non-human experimental subject, indicates a condition in which the subject has shown unequivocally a proof of dependency, i.e., somatic signs of withdrawal) rats show a profound reduction of spontaneous firing rate and burst firing of antidromically identified Nucleus accumbens (Nacc)-projecting ventral tegmental area (VTA) DA-containing neurons in rats (Diana et al., 1993) and mice (Bailey et al., 2001) resulting in a concomitant reduction of microdialysate DA in the Nacc (Rossetti et al., 1992; Diana et al., 1993; Barak et al., 2011). Further, the reduced dopaminergic activity outlasts somatic signs of alcohol-withdrawal (Diana et al., $1996,2003)$ thereby suggesting a role for DA in the lasting consequences of alcohol dependence while excluding the possibility of a DA role in somatic aspects of withdrawal. Further, original (predependence) DA levels in the Nacc are restored when ethanol is self (Weiss et al., 1996) and/or passively administered (Diana et al., 1993, 1996). These observations are paralleled by intracranial self stimulation (ICSS) studies showing that ethanol-withdrawn rats are capable of maintaining the ICSS behavior provided that the stimulus current intensity is increased (Schulteis et al., 1995). This important observation strongly indicates that the neural substrate responsible for maintaining the ICSS behavior is hyperpolarized, or more refractory, in the alcohol-dependent subject as compared with its control. Since the neural substrate of ICSS involves DA axons (Yeomans, 1989; Yeomans et al., 1993) near the stimulating electrode, the results are complementary to those reported above and well support a deficitary function of DA neurons. In addition, the perseverance of the reduction in DA activity (beyond resolution of somatic signs of withdrawal) has also been documented in morphine-dependent rats (Diana et al., 1999), while a dichotomy between DA function and somatic withdrawal has been observed in cannabinoid-withdrawn rats (Diana et al., 1998). Similarly, conditioned heroin withdrawal decreases reward sensitivity (Kenny et al., 2006) which persists well beyond the initial phase of withdrawal. These findings, observed across different addicting compounds and experimental conditions, suggest that DA hypofunction persists over time, although reverting to "normality" (Diana et al., 1999, 2006), eventually with species-specific time course.
In addition to basic literature, reports in humans are also supportive of a compromised role of DA transmission in alcoholics. While alcohol increases DA release in healthy subjects (Boileau et al., 2003) with some gender differences (Urban et al., 2010), a reduced number of DA receptors has been observed (Volkow et al., 1996; Martinez et al., 2005) in alcoholics that appears to be accompanied by a blunted DA release (Martinez et al., 2005, 2007; Volkow et al., 2007). While the reduced number of DA receptors could be, at first sight, be viewed as suggesting an increased DA release, it should be noted that by administering the DA inhibitor alpha methyl-para-tyrosine, Martinez et al. (2009) were able to exclude this possibility. Indeed, while healthy controls do show an increased raclopride binding after acute alpha methyl-paratyrosine administration, cocaine-dependent subjects do not (or to a significantly lesser extent; Martinez et al., 2009). Similar results were obtained with the dopamine releasing agent methylphenidate (Volkow et al., 2007) and amphetamine (Martinez et al., 2005) in alcoholics. Notably, artificially increasing the brain levels of DAD2 receptors, using a replication-deficient adenoviral vector containing the rat CDNA insert for DAD2 into the Nacc, reduces alcohol intake in spontaneously drinking rats, thereby offering the counterproof that a potentiation of DA transmission may have beneficial effects on alcohol-seeking and alcohol-taking, in experimental models (Thanos et al., 2001, 2004). In line with this conclusion, a spontaneous high number of DA D2 receptors has been shown to have a protective role in non-alcoholic members of alcoholic families (Volkow et al., 2006). These findings further support the notion that the number of DA receptors (and consequently DA transmission) inversely correlates with alcohol drinking.

These observations may suggest that "boosting" DA neurons to produce more available DA in the synaptic cleft could alleviate some of the symptoms of addiction and alcoholism, thereby acquiring a therapeutic character. In theory, this could be achieved by two different strategies: (1) DA-potentiating drugs and (2) TMS. Both possibilities are discussed below.

\section{DOPAMINE-POTENTIATING DRUGS}

Although medications that increase DA activity could be effective in treating alcohol abuse disorders, conflicting results have been produced (Swift, 2010). For example, it was suggested that the DA agonist bromocriptine reduced drinking in alcoholics (Lawford et al., 1995), but a randomized, double-blind, placebo-controlled study using a long-acting injectable bromocriptine preparation in 366 alcoholic-dependent individuals did not find difference in alcohol relapse between medication and placebo (Naranjo et al., 1997). Another example is the stimulant medication modafinil (DA indirect agonist), found to improve cognition in 40 alcoholics with organic brain syndrome, but effects on drinking could not be measured (Saletu et al., 1990). However, modafinil reduced cocaine use in a placebo-controlled study with 62 cocainedependent individuals (Dackis and O'Brien, 2005), while another trial did not find differences between modafinil and placebo tested for methamphetamine users (Shearer et al., 2010). While evidence for the use of DA agonists as a treatment for alcohol and/or substance use disorders is inconclusive (Swift, 2010), there has been a revived interest for these drugs, possibly because adequate 
neurobiological rationale (Melis et al., 2005) is now available. For example, aripiprazole (Semba et al., 1995; Burris et al., 2002; Shapiro et al., 2003) a partial DA agonist which in principle should antagonize DA when tone is high, whereas should increase DA transmission when basic tone is low, represents a proposed treatment for alcohol abuse disorders (Kenna et al., 2009). Human laboratory alcohol studies have shown that aripiprazole reduces drinking (Kranzler et al., 2008), especially in the more impulsive alcoholic (Voronin et al., 2008). An fMRI study demonstrated that aripiprazole significantly attenuates neural activity in the ventral striatum in response to alcohol cues (Myrick et al., 2010) thereby suggesting a therapeutic potential for cue-induced relapse. Further, a 12-week, double-blind, placebo-controlled treatment study with 295 alcohol-dependent individuals found that aripiprazole initially decreased heavy drinking days compared to placebo, but this significant effect was not present when the target dose of $30 \mathrm{mg}$ was reached (Anton et al., 2008). This trial also showed greater side-effects and greater study discontinuation in the aripiprazole arm, as compared to placebo (Anton et al., 2008). Interestingly, an open-label study of aripiprazole (Martinotti et al., 2009) and a recent human laboratory study (Kenna et al., 2009) suggests that lower doses of aripiprazole (5-15 mg per day) may be better tolerated and still reduce drinking with effects on relapse comparable to those obtained with the opiate antagonist naltrexone (Martinotti et al., 2009).

In summary, dopamine plays a key role in the addiction process, but significant side-effects have limited the use of medications that work directly on the dopaminergic system. The use of DA partial agonists with lower side effect profiles, and appropriate dosing represent important directions for future research in this area.

\section{TRANSCRANIAL MAGNETIC STIMULATION}

Increasing DA tone with appropriate pharmacological tools, is only one of the possible strategies. Endogenous activity of DAcontaining neurons can be augmented with non-pharmacological tools such as TMS (Strafella et al., 2001) thereby providing, in principle, an adjunct to the "therapeutic arsenal" against addiction, endowed with lesser systemic side-effects and limited contraindications. However, while the rationale is "neurochemical" for pharmacological agents (neurotransmitter receptors, brain area etc.), it must be anatomically based for TMS. Being that DA-containing neurons are located deeply in the brainstem (thereby making the neurons inaccessible to direct TMS stimuli) it becomes unavoidable to reach them indirectly through neurons located elsewhere in the brain. The dorsolateral prefrontal cortex (DLPfcx) by projecting monosynaptically to the rat (Carr and Sesack, 2000) and primate (Frankle et al., 2006) VTA may serve this function. These studies show a projection from the PFC to midbrain DA neurons, terminating both within the $\mathrm{SN}$ proper as well as in the VTA. They arise from a broad region of the PFC, including the DLPfcx, cingulate, and orbital cortices. Indeed, these pyramidal neurons (Figure 1) could be exploited as the primary target of the TMS stimulus and their increased activity to produce, ultimately, an enhancement in DA availability in the synaptic cleft in the Nacc. Schematically, the hypothesized circuit (Figure 2) would be the following: TMS $\rightarrow$ DLPfcx $\rightarrow$ VTA $\rightarrow$ DA increase in forebrain projection site (i.e., Nacc). In this context, it is imperative

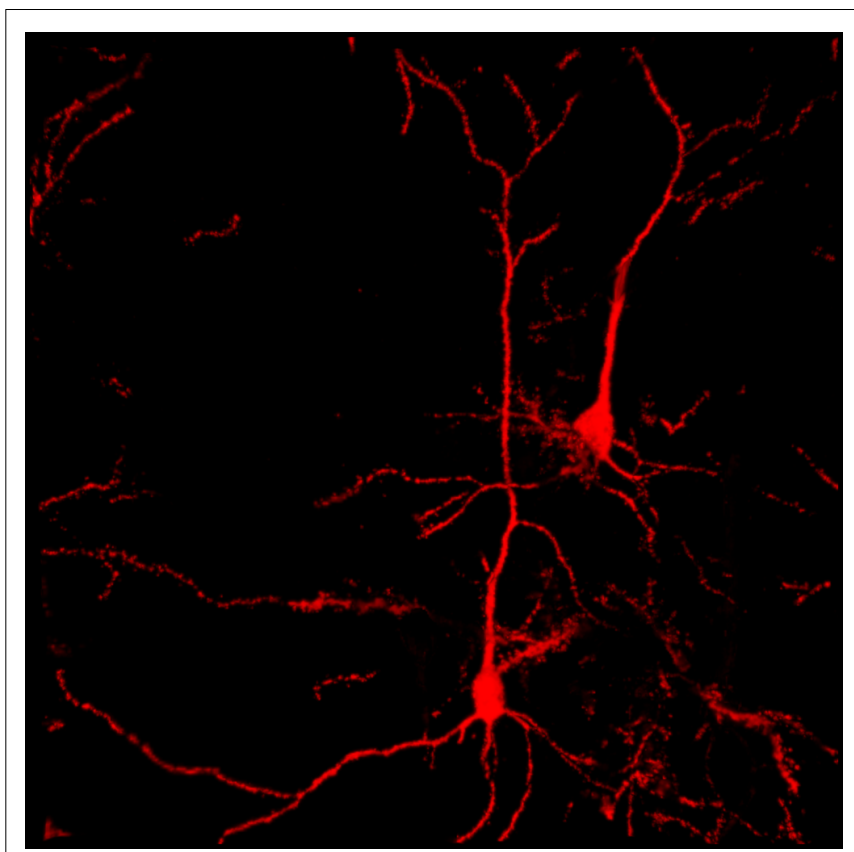

FIGURE 1 | Confocal reconstruction of Golgi-stained pyramidal neurons from DLPfcx obtained by a projection of $\mathbf{5 5}$ scans for a depth of $\mathbf{2 7 . 5} \mu \mathbf{m}$ in the $\mathbf{z}$-axis. DLPfxc may represent a useful target for rTMS stimulation.

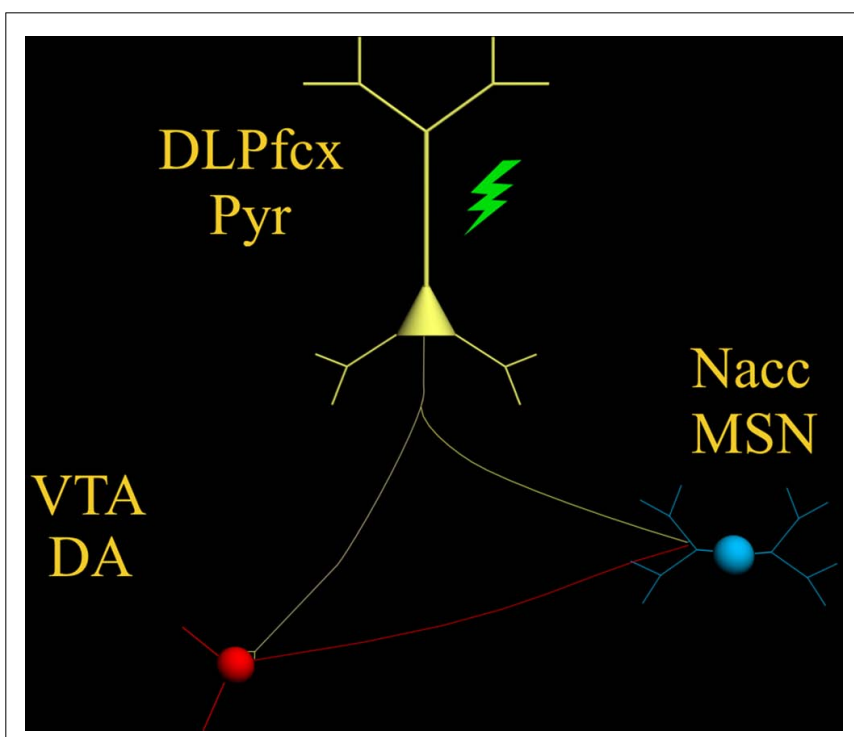

FIGURE 2 |The scheme illustrates the proposed circuit to be activated by the TMS stimulus (green) which, by activating the pyramidal neuron (yellow) with its neurotransmitter glutamate, would excite: (1) DA-containing neurons of the VTA (red) and (2) MSN of the Nacc (blue).

to employ stimulation parameters consonant with the physiological activity of the system under study to restore pre-drug DA levels. For instance, it has been shown that DLPfcx stimulation produces bursts in rat DA neurons (Gariano and Groves, 1988; Murase et al., 1993), highlighting the importance of stimulation 
parameters. Indeed, burst firing is more efficacious than single spiking (of identical frequency but evenly spaced action potentials) in inducing DA release in terminal areas (Gonon, 1988; Manley et al., 1992). Consistently, the role of DLPfcx in regulating basal DA activity through the VTA has been reported (Taber et al., 1995; Karreman and Moghaddam, 1996).

Among the various factors that are likely to influence its efficacy, the importance of the baseline cortical activation state on the impact of TMS is fundamental (Silvanto and Pascual-Leone, 2008). This state-dependency is key as the neural impact of any external stimulus represents an interaction with the ongoing brain activity at the time of stimulation. The effects of any external stimulus are therefore not only determined by the properties of that stimulus but also by the activation state of the brain. Accordingly, it has been shown that baseline cortical activity determines whether TMS hampers or hastens behavior (Silvanto et al., 2008). The state-dependency principle described above would also apply to the state of the DA system. The hypodopaminergic state (Melis et al., 2005) should then "amplify" the effect of TMS as compared with that expected in a normo-functioning DA system.

The responsivity of the neuron(s) to electrical and synaptic stimuli is strictly dependent on its morphological features, which in turn, are deeply modified by drugs of abuse (Robinson and Kolb, 2004) and withdrawal from chronic treatment with opiates (Sklair-Tavron et al., 1996; Spiga et al., 2003, 2005), cannabis derivatives/analogs (Spiga et al., 2010), and psychostimulants (Robinson and Kolb, 1997) have been shown to produce reductions in DA cells size (Sklair-Tavron et al., 1996; Spiga et al., 2003), paralleled by persistently (Diana et al., 2006) altered patterns of synaptic connectivity, and spines density in the Nacc and Pfcx (Robinson and Kolb, 1997). These architectural changes would be expected to modify intrinsic spontaneous action potential generating capacity and responsiveness of the system to the TMS stimuli. Accordingly, realistic computational analysis (Spiga et al., 2010) of cannabis-dependent rats, generated by input of experimentally verified morphometrical and electrophysiological properties, predicts a lower action potential generation of Nacc medium spiny neuron (MSN). These results suggest that MSN, of cannabis-dependent rats are likewise hypofunctional. Considering that the main drive of these neurons is cortical glutamate (Glu; see discussion in Spiga et al., 2010, and references therein; Kalivas and $\mathrm{Hu}, 2006)$ it raises the possibility of a reduction of Glu as a causal factor. This finding, thus offers the additional possibility that stimulation of these units through TMS may be advantageous in restoring pre-drug physiological activity. Indeed, TMS cortical application should increase the activity of glutamatecontaining cortico-fugal fibers monosynaptically impinging upon the spine's heads of Nacc MSN (Groenewegen et al., 1991). Considering the fundamental role Glu plays in synaptic plasticity (Russo

\section{REFERENCES}

Ahlenius, S., Carlsson, A., Engel, J., Svensson, T., and Södersten, P. (1973). Antagonism by alpha methyltyrosine of the ethanolinduced stimulation and euphoria in man. Clin. Pharmacol. Ther. 14, 586-591.
Amiaz, R., Levy, D., Vainiger, D., Grunhaus, L., and Zangen, A. (2009). Repeated high-frequency over the dorsolateral prefrontal cortex reduces cigarette craving and consumption. Addiction 104, 653-660. transcranial magnetic stimulation

et al., 2010), its role could also be exploited in LTP-like stimulation parameters, ultimately aimed at producing lasting and enduring restoration of original physiological activity. These characteristics must be considered and coherently inserted into a framework to obtain optimal stimulation parameters. In vivo recordings of VTA-projecting DLPfcx neurons do fire spontaneously around 4$6 \mathrm{~Hz}$ (Pistis et al., 2001) and a TMS stimulus frequency of $10 \mathrm{~Hz}$ could be a reasonable frequency to obtain a significant increase in VTA-projecting neurons aimed at stimulating the "deficient" dopamine system and its post-synaptic counterpart (i.e., MSN of the Nacc).

Another factor to be considered is that all previous studies (see above) applied the TMS stimulus monolaterally, yet obtaining a reduction of alcohol craving (Mishra et al., 2010). While alcohol intake was not measured, and contralateral effects cannot be excluded a priori, it is possible that application of TMS bilaterally, as in the case of the H-coil (Feil and Zangen, 2010), would yield stronger cortical activation (larger number of fibers activated) with an increased probability of a significant increment of bilateral DA release. It should be noted that unilateral TMS application has already been reported to increase DA release (Strafella et al., 2001) omolaterally in the human striatum, as well as in rodents (Keck et al., 2002; Zangen and Hyodo, 2002), and even in morphine-withdrawn rats (Erhardt et al., 2004), thereby supporting the rationale outlined above. Although Strafella et al. (2001) proposed activation of (Glu-containing) cortico-fugal fibers making synaptic contact with DA-containing terminals in the ventral striatum, to explain their results, it should be noted that the existence of axo-axonic contacts has always being questioned based on the lack of appropriate anatomical observations (Groenewegen et al., 1991; Meredith et al., 2008).

While many technical details for optimal stimulation parameters need further investigation and optimization, the TMS appears to deserve careful experimental scrutiny as a potential therapeutic tool in alcoholics and other addicts. Indeed, with its nearly absent systemic effects, minimal side-effects, and a low degree of invasiveness, TMS may offer the first opportunity for an efficacious, non-pharmacological, therapeutic tool in alcoholism and other chemical dependencies. If appropriately combined with a solid neurobiological rationale (DA system), it may offer a unique opportunity for developing further the first "electrophysiological" approach in studying and eventually treating the devastating and widespread brain disease of addiction.

\section{ACKNOWLEDGMENTS}

This work was supported, in part, by grants from MIUR (PRIN. N $\left.{ }^{\circ} 2004052392\right)$ and Dipartimento Politiche Antidroga. The author wish to thank S. Spiga for elaborating iconographic material presented.

Anton, R. F., Kranzler, H., Breder, C., Marcus, R. N., Carson, W. H., and Han, J. (2008). A randomized, multicenter, double-blind, placebocontrolled study of the efficacy and safety of aripiprazole for the treatment of alcohol dependence. J. Clin. Psychopharmacol. 28, 5-12.
Bailey, C. P., O'Callaghan, M. J. Croft, A. P., Manley, S. J., and Little, H. J. (2001). Alterations in mesolimbic dopamine function during the abstinence period following chronic ethanol consumption. Neuropharmacology 41, 989-999. 
Barak, S., Carnicella, S., Yowell, Q. W., and Ron, D. (2011). Glial cell line-derived neurotrophic factor reverses alcoho-induced allostasis of the mesolimbic dopaminergic system: implications for alcohol reward and seeking. J. Neurosci. 31, 9885-9894.

Barr, M. S., Fitzgerald, P. B., Farzan, F., George, T. P., and Daskalakis, Z. J. (2008). Transcranial magnetic stimulation to understand the pathophysiology and treatment of substance use disorders. Curr. Drug Abuse Rev. 1, 328-339.

Boileau, I., Assaad, J. M., Pihl, R. O., Benkelfat, C., Leyton, M., Diksic, M., Tremblay, R. E., and Dagher, A. (2003). Alcohol promotes dopamine release in the human nucleus accumbens. Synapse 15, 226-231.

Boutros, N. N., Lisanby, S. H., McClainFurmanski, D., Oliwa, G., Gooding, D., and Kosten, T. R. (2005). Cortical excitability in cocaine-dependent patients: a replication and extension of TMS findings. J. Psychiatr. Res. 39, 295-302.

Boutros, N. N., Lisanby, S. H., Tokuno, H., Torello, M. W., Campbell, D., Berman, R., Malison, R., Krystal, J. H., and Kosten, T. (2001). Elevated motor threshold in drugfree, cocaine-dependent patients assessed with transcranial magnetic stimulation. Biol. Psychiatry 49, 369-373.

Burris, K. D., Molski, T. F., Xu, C., Ryan, E., Tottori, K., Kikuchi, T., Yocca, F. D., and Molinoff, P. B. (2002). Aripiprazole, a novel antipsychotic, is a high-affinity partial agonist at human dopamine D2 receptors. J. Pharmacol. Exp. Ther. 302, 381-389.

Carr, D. B., and Sesack, S. R. (2000). Projections from the rat prefrontal cortex to the ventral tegmental area: target specificity in the synaptic associations with mesoaccumbens and mesocortical neurons. J. Neurosci. 20, 3864-3873.

Chandler, R. K., Fletcher, B. W., and Volkow, N. D. (2009). Treating drug abuse and addiction in the criminal justice system: improving public health and safety. JAMA 301, 183-190.

Conte, A., Attilia, M. L., Gilio, F., Iacovelli, E., Frasca, V., Bettolo, C. M., Gabriele, M., Giacomelli, E., Prencipe, M., Berardelli, A., Ceccanti, M., and Inghilleri, M. (2008). Acute and chronic effects of ethanol on cortical excitability. Clin. Neurophysiol. 119, 667-674.

Dackis, C., and O'Brien, C. (2005). Neurobiology of addiction: treatment and public policy ramifications. Nat. Neurosci. 8, 1431-1436.

Di Chiara, G., and Imperato, A. (1988). Drugs abused by humans preferentially increase synaptic dopamine concentrations in the mesolimbic system of freely moving rats. Proc. Natl. Acad. Sci. U.S.A. 85, 5274-5278.

Diana, M., Brodie, M., Muntoni, A., Puddu, M. C., Pillolla, G., Steffensen, S., Spiga, S., and Little, H. J. (2003). Enduring effects of chronic ethanol in the CNS: basis for alcoholism. Alcohol. Clin. Exp. Res. 27, 354-361.

Diana, M., Melis, M., Muntoni, A. L., and Gessa, G. L. (1998). Mesolimbic dopaminergic decline after cannabinoid withdrawal. Proc. Natl. Acad. Sci. U.S.A. 18, 10269-10273.

Diana, M., Muntoni, A. L., Pistis, M., Melis, M., and Gessa, G. L. (1999). Lasting reduction in mesolimbic dopamine neuronal activity after morphine withdrawal. Eur. J. Neurosci. 11, 1037-1041.

Diana, M., Pistis, M., Carboni, S., Gessa, G. L., and Rossetti, Z. L. (1993). Profound decrement of mesolimbic dopaminergic neuronal activity during ethanol withdrawal syndrome in rats: electrophysiological and biochemical evidence. Proc. Natl. Acad. Sci. U.S.A. 90, 7966-7969.

Diana, M., Pistis, M., Muntoni, A., and Gessa, G. L. (1996). Mesolimbic dopaminergic reduction outlasts ethanol withdrawal syndrome: Evidence of protracted abstinence. $\mathrm{Neu}$ roscience 71, 411-415.

Diana, M., Spiga, S., and Acquas, E. (2006). Persistent and reversible morphine withdrawal-induced morphological changes in the nucleus accumbens. Ann. N. Y. Acad. Sci. 1074, 446-457.

Erhardt, A., Sillaber, I., Welt, T., Müller, M. B., Singewald, N., and Keck, M. E. (2004). Repetitive transcranial magnetic stimulation increases the release of dopamine in the nucleus accumbens shell of morphine-sensitized rats during abstinence. Neuropsychopharmacology 29, 2074-2080.

Feil, J., and Zangen, A. (2010). Brain stimulation in the study and treatment of addiction. Neurosci. Biobehav. Rev. 34, 559-574.

Frankle, W. G., Laruelle, M., and Haber, S. N. (2006). Prefrontal cortical projections to the midbrain in primates: evidence for a sparse connection. Neuropsychopharmacology 31, 1627-1636.

Gariano, R. F., and Groves, P. M. (1988). Burst firing induced in midbrain dopamine neurons by stimulation of the medial prefrontal and anterior cingulate cortices. Brain Res. 462 , 194-198.

Gonon, F. (1988). Nonlinear relationship between impulse flow and dopamine released by rat midbrain dopaminergic neurons as studied by in vivo electrochemistry. Neuroscience $24,19-28$.

Groenewegen, H. J., Berendse, H. W., Meredith, G. E., Haber, S. N., Voorn, P., Wolters, J. G., and Lohman, A. H. M. (1991). "Functional anatomy of the ventral, limbic system-innervated striatum," in The Mesolimbic Dopamine System: From Motivation to Action, eds P. Willner and J. Scheel-Krüger (New York: Wiley), 19-59.

Hyman, S. E. (2007). The neurobiology of addiction: implications for voluntary control of behavior. Am. J. Bioeth. 7, 8-11.

Kalivas, P. W., and Hu, X. T. (2006). Exciting inhibition in psychostimulation addiction. Trends Neurosci. 29, 610-616.

Karreman, M., and Moghaddam, B. (1996). The prefrontal cortex regulates the basal release of dopamine in the limbic striatum: an effect mediated by ventral tegmental area. $J$. Neurochem. 66, 589-598.

Keck, M. E., Welt, T., Müller, M. B., Erhardt, A., Ohl, F., Toschi, N., Holsboer, F., and Sillaber, I. (2002). Repetitive transcranial magnetic stimulation increases the release of dopamine in the mesolimbic and mesostriatal system. Neuropharmacology 43, 101-109.

Kenna, G. A., Leggio, L., and Swift, R. M. (2009). A safety and tolerability laboratory study of the combination of aripiprazole and topiramate in volunteers who drink alcohol. Hum. Psychopharmacol. 24, 465-472.

Kenny, P. J., Chen, S. A., Kitamura, O., Markou, A., and Koob, G. F. (2006). Conditioned withdrawal drives heroin consumption and decreases reward sensitivity. J. Neurosci. 26, 5894-5900.

Kobayashi, M., and Pascual-Leone, A. (2003). Transcranial magnetic stimulation in neurology. Lancet Neurol. 2, 145-156.

Koob, G. F., Kenneth Lloyd, G., and Mason, B. J. (2009). Development of pharmacotherapies for drug addiction: a Rosetta stone approach. Nat. Rev. Drug Discov. 8, 500-515.

Koob, G. F., and Volkow, N. D. (2010). Neurocircuitry of addiction. Neuropsychopharmacology 35, 217-238.
Kranzler, H. R., Covault, J., PierucciLagha, A., Chan, G., Douglas, K., Arias, A. J., and Oncken, C. (2008). Effects of aripiprazole on subjective and physiological responses to alcohol. Alcohol. Clin. Exp. Res. 32, 573-579.

Lang, N., Hasan, A., Sueske, E., Paulus, W., and Nitsche, M. A. (2008) Cortical hypoexcitability in chronic smokers? A transcranial magnetic stimulation study. Neuropsychopharmacology 33, 2517-2523.

Lawford, B. R., Young, R. M., Rowell, J. A., Qualichefski, J., Fletcher, B. H., Syndulko, K., Ritchie, T., and Noble, E. P. (1995). Bromocriptine in the treatment of alcoholics with the D2 dopamine receptor Al allele. Nat. Med. 1,337-341.

Leggio, L., Cardone, S., Ferrulli, A., Kenna, G. A., Diana, M., Swift, R. M., and Addolorato, G. (2010). Turning the clock ahead: potential preclinical and clinical neuropharmacological targets for alcohol dependence. Curr. Pharm. Des. 16, 2159-2181.

Manley, L. D., Kuczenski, R., Segal, D. S. Young, S. J., and Groves, P. M. (1992). Effects of frequency and pattern of medial forebrain bundle stimulation on caudate dialysate dopamine and serotonin. J. Neurochem. 58, 1491-1498.

Martinez, D., Gil, R., Slifstein, M., Hwang, D. R., Huang, Y., Perez A., Kegeles, L., Talbot, P., Evans, S., Krystal, J., Laruelle, M., and AbiDargham, A. (2005). Alcohol dependence is associated with blunted dopamine transmission in the ventral striatum. Biol. Psychiatry 58, 779-786.

Martinez, D., Greene, K., Broft, A., Kumar, D., Liu, F., Narendran, R., Slifstein, M., Van Heertum, R., and Kleber, H. D. (2009). Lower level of endogenous dopamine in patients with cocaine dependence: findings from PET imaging of $\mathrm{D}(2) / \mathrm{D}(3)$ receptors following acute dopamine depletion. Am. J. Psychiatry 166, 1170-1177.

Martinez, D., Kim, J. H., Krystal, J., and Abi-Dargham, A. (2007). Imaging the neurochemistry of alcohol and substance abuse. Neuroimaging Clin. N. Am. 17, 539-555.

Martinotti, G., Di Nicola, M., Di Giannantonio, M., and Janiri, L. (2009). Aripiprazole in the treatment of patients with alcohol dependence: a double-blind, comparison trial vs. naltrexone. J. Psychopharmacol. 23, 123-129. 
Melis, M., Spiga, S., and Diana, M. (2005). The dopamine hypothesis of drug addiction: hypodopaminergic state. Int. Rev. Neurobiol. 63, 101-154.

Meredith, G. E., Baldo, B. A., Andrezjewsky, M. E., and Kelley, A. E. (2008). The structural basis for mapping behavior onto the ventral striatum and its subdivisions. Brain Struct. Funct. 213, 17-27.

Mishra, B. R., Nizamie, S. H., Das, B., and Praharaj, S. K. (2010). Efficacy of repetitive transcranial magnetic stimulation in alcohol dependence: a sham-controlled study. Addiction 105, 49-55.

Murase, S., Grenhoff, J., Chouvet, G., Gonon, F. G., and Svensson, T. H. (1993). Prefrontal cortex regulates burst firing and transmitter release in rat mesolimbic dopamine neurons studied in vivo. Neurosci. Lett. 157, 53-56.

Myrick, H., Li, X., Randall, P. K., Henderson, S., Voronin, K., and Anton, R. F. (2010). The effect of aripiprazole on cue-induced brain activation and drinking parameters in alcoholics. J. Clin. Psychopharmacol. 30, 365-372.

Naranjo, C. A., Dongier, M., and Bremner, K. E. (1997). Long-acting injectable bromocriptine does not reduce relapse in alcoholics. Addiction 92, 969-978.

Padberg, F., and George, M. S. (2009). Repetitive transcranial magnetic stimulation of the prefrontal cortex in depression. Exp. Neurol. 219, 2-13.

Pistis, M., Porcu, G., Melis, M., Diana, M., and Gessa, G. L. (2001). Effects of cannabinoids on prefrontal neuronal responses to ventral tegmental area stimulation. Eur. J. Neurosci. 14, 96-102.

Politi, E., Fauci, E., Santoro, A., and Smeraldi, E. (2008). Daily sessions of transcranial magnetic stimulation to the left prefrontal cortex gradually reduce cocaine craving. Am. J. Addict. 17, 345-346.

Robinson, T. E., and Kolb, B. (1997). Persistent structural modifications in nucleus accumbens and prefrontal cortex neurons produced by previous experience with amphetamine. J. Neurosci. 17, 8491-8497.

Robinson, T. E., and Kolb, B. (2004). Structural plasticity associated with exposure to drugs of abuse. Neuropharmacology 47(Suppl. 1), 33-46.
Rossetti, Z. L., Melis, F., Carboni, S., Diana, M., and Gessa, G. L. (1992). Alcohol withdrawal in rats is associated with a marked fall in extraneuronal dopamine. Alcohol. Clin. Exp. Res. 16, 529-532.

Russo, S. J., Dietz, D. M., Dumitriu, D., Morrison, J. H., Malenka, R. C., and Nestler, E. J. (2010). The addicted synapse: mechanisms of synaptic and structural plasticity in nucleus accumbens. Trends Neurosci. 33, 267-276.

Saletu, B., Saletu, M., Grünberger, J., Frey, R., Zatschek, I., and Mader, R. (1990). On the treatment of the alcoholic organic brain syndrome with an alpha-adrenergic agonist modafinil: double-blind, placebo-controlled clinical, psychometric and neurophysiological studies. Prog. Neuropsychopharmacol. Biol. Psychiatry 14, 195-214.

Schulteis, G., Markou, A., Cole, M., and Koob, G. F. (1995). Decreased brain reward produced by ethanol withdrawal. Proc. Natl. Acad. Sci. U.S.A. 20, 5880-5884.

Semba, J., Watanabe, A., Kito, S., and Toru, M. (1995). Behavioural and neurochemical effects of OPC14597, a novel antipsychotic drug, on dopaminergic mechanisms in rat brain. Neuropharmacology 34, 785-791.

Shapiro, D. A., Renock, S., Arrington, E., Chiodo, L. A., Liu, L. X., Sibley, D. R., Roth, B. L., and Mailman, R. (2003). Aripiprazole, a novel atypical antipsychotic drug with a unique and robust pharmacology. Neuropsychopharmacology 28, 1400-1411.

Shearer, J., Shanahan, M., Darke, S., Rodgers, C., van Beek, I., McKetin, R., and Mattick, R. P. (2010). A cost-effectiveness analysis of modafinil therapy for psychostimulant dependence. Drug Alcohol Rev. $29,235-242$.

Silvanto, J., Cattaneo, Z., Battelli, L., and Pascual-Leone, A. (2008). Baseline cortical excitability determines whether TMS disrupts or facilitates behavior. J. Neurophysiol. 99, 2725-2730.

Silvanto, J., and Pascual-Leone, A. (2008). State-dependency of transcranial magnetic stimulation. Brain Topogr. 21, 1-10.

Sklair-Tavron, L., Shi, W. X., Lane, S. B., Harris, H. W., Bunney, B. S., and Nestler, E. J. (1996). Chronic morphine induces visible changes in the morphology of mesolimbic dopamine neurons. Proc. Natl. Acad. Sci. U.S.A. 1, 11202-11207.

Spiga, S., Lintas, A., Migliore, M., and Diana, M. (2010). Altered architecture and functional consequences of the mesolimbic dopamine system in cannabis dependence. Addict Biol. 15, 266-276.

Spiga, S., Puddu, M. C., Pisano, M., and Diana, M. (2005). Morphine withdrawal-induced morphological changes in the nucleus accumbens. Eur. J. Neurosci. 22, 2332-2340.

Spiga, S., Serra, G. P., Puddu, M. C., Foddai, M., and Diana, M. (2003). Morphine withdrawal-induced abnormalities in the VTA: confocal laser scanning microscopy. Eur. J. Neurosci. 17, 605-612.

Strafella, A. P., Paus, T., Barrett, J., and Dagher, A. (2001). Repetitive transcranial magnetic stimulation of the human prefrontal cortex induces dopamine release in the caudate nucleus. J. Neurosci. 21, RC157.

Sundaresan, K., Ziemann, U., Stanley, J., and Boutros, N. (2007). Cortical inhibition and excitation in abstinent cocaine-dependent patients: a transcranial magnetic stimulation study. Neuroreport 18 289-292.

Swift, R. M. (2010). Medications acting on the dopaminergic system in the treatment of alcoholic patients. Curr. Pharm. Des. 16, 2136-2140.

Taber, M. T., Das, S., and Fibiger, H. C. (1995). Cortical regulation of subcortical dopamine release: mediation via the ventral tegmental area. J. Neurochem. 65 1407-1410.

Thanos, P. K., Taintor, N. B., Rivera, S. N., Umegaki, H., Ikari, H., Roth, G., Ingram, D. K., Hitzemann, R., Fowler, J. S., Gatley, S. J., Wang, G. J., and Volkow, N. D. (2004). DRD2 gene transfer into the nucleus accumbens core of the alcohol preferring and nonpreferring rats attenuates alcohol drinking. Alcohol. Clin. Exp. Res. 28, 720-728.

Thanos, P. K., Volkow, N. D., Freimuth, P., Umegaki, H., Ikari, H., Roth, G., Ingram, D. K., and Hitzemann, R. (2001). Overexpression of dopamine D2 receptors reduces alcohol selfadministration. J. Neurochem. 78, 1094-1103.

Urban, N. B., Kegeles, L. S., Slifstein, M., Xu, X., Martinez, D., Sakr, E., Castillo, F., Moadel, T., O'Malley, S. S., Krystal, J. H., and Abi-Dargham, A. (2010). Sex differences in stri- atal dopamine release in young adults after oral alcohol challenge: a positron emission tomography imaging study with [11C] raclopride. Biol. Psychiatry 68, 689-696.

Volkow, N. D., Wang, G. J., Begleiter, H., Porjesz, B., Fowler, J. S., Telang, F., Wong, C., Ma, Y., Logan, J., Goldstein, R., Alexoff, D., and Thanos, P. K. (2006). High levels of dopamine $\mathrm{D} 2$ receptors in unaffected members of alcoholic families: possible protective factors. Arch. Gen. Psychiatry 63, 999-1008

Volkow, N. D., Wang, G. J., Fowler, J. S., Logan, J., Hitzemann, R., Ding, Y. S., Pappas, N., Shea, C., and Piscani, K. (1996). Decreases in dopamine receptors but not in dopamine transporters in alcoholics. Alcohol. Clin. Exp. Res. 20, 1594-1598.

Volkow, N. D., Wang, G. J., Telang, F., Fowler, J. S., Logan, J., Jayne, M., Ma, Y., Pradhan, K., and Wong, C. (2007). Profound decreases in dopamine release in striatum in detoxified alcoholics: possible orbitofrontal involvement. J. Neurosci. 27, 12700-12706.

Voronin, K., Randall, P., Myrick, H., and Anton, R. (2008). Aripiprazole effects on alcohol consumption and subjective reports in a clinical laboratory paradigm-possible influence of self-control. Alcohol. Clin. Exp. Res. 32, 1954-1961.

Weiss, F., Parsons, L. H., Schulteis, G., Hyytia, P., Lorang, M. T. Bloom, F. E., and Koob, G. F. (1996). Ethanol self-administration restores withdrawal-associated deficiencies in accumbal dopamine and 5-hydroxytryptamine release in dependent rats. J. Neurosci. 16, 3474-3485.

Wise, R. A. (1980). Action of drugs of abuse on brain reward systems. Pharmacol. Biochem. Behav. 13(Suppl. 1), 213-223.

Wise, R. A. (1987). The role of reward pathways in the development of drug dependence. Pharmacol. Ther. 35, 227-263.

Yeomans, J. S. (1989). Two substrates for medial forebrain bundle selfstimulation: myelinated axons and dopamine axons. Neurosci. Biobehav. Rev. 13, 91-98.

Yeomans, J. S., Mathur, A., and Tampakeras, M. (1993). Rewarding brain stimulation: role of tegmental cholinergic neurons that activate dopamine neurons. Behav. Neurosci. 107, 1077-1087.

Zangen, A., and Hyodo, K. (2002). Transcranial magnetic stimulation 
induces increases in extracellular levels of dopamine and glutamate in the nucleus accumbens. Neuroreport 13, 2401-2405.

Conflict of Interest Statement: The author declares that the research was conducted in the absence of any commercial or financial relationships that could be construed as a potential conflict of interest.

Received: 14 September 2011; paper pending published: 07 October 2011; accepted: 02 November 2011; published online: 29 November 2011.
Citation: Diana M (2011) The dopamine hypothesis of drug addiction and its potential therapeutic value. Front. Psychiatry 2:64. doi: 10.3389/fpsyt.2011.00064

This article was submitted to Frontiers in Addictive Disorders, a specialty of Frontiers in Psychiatry.
Copyright $(2011$ Diana. This is an openaccess article subject to a non-exclusive license between the authors and Frontiers Media SA, which permits use, distribution and reproduction in other forums, provided the original authors and source are credited and other Frontiers conditions are complied with. 